\title{
Análise comparativa regional de indicadores de inovação tecnológica empresarial: contribuição a partir dos dados da pesquisa industrial de inovação tecnológica
}

Elisa Maria Pinto da Rocha

\begin{abstract}
Doutora em Ciências da Informação pela Universidade Federal de Minas Gerais (2003); Professora da Escola de Governo (Programa de Mestrado e Curso Superior de Administração Pública); Professora Colaboradora do Programa de Mestrado Profissionalizante de Engenharia da Universidade de Itaúna; Pesquisadora do Centro de Estatística e Informações (CEI/FJP).
\end{abstract}

Simone Cristina Dufloth

\begin{abstract}
Doutora em Ciências da Informação pela Universidade Federal de Minas Gerais; Pesquisadora em Ciência e Tecnologia e Gerente de Ensino e Pesquisa da Fundação João Pinheiro; Professora Titular do Centro Universitário UNA.
\end{abstract}

Este artigo apresenta uma análise de indicadores de inovação tecnológica empresarial. A metodologia baseiase na análise desagregada, segundo regiões do País, dos dados produzidos pelo IBGE na Pesquisa Industrial de Inovação Tecnológica. A análise de tais indicadores confirma a idéia de que a inovação envolve elementos outros que não apenas aqueles essencialmente econômicos. A região Sudeste - líder nacional em termos de capacidade econômica de produção - não apresenta o mesmo destaque no que diz respeito à amplitude da inovação tecnológica. As empresas das regiões Nordeste, Norte e Sul são aquelas que realizam maior esforço inovador, comparativamente às outras regiões, e são também as que apresentam maior amplitude de inovação. Os resultados sugerem que a preocupação com a proteção do conhecimento por meio de patentes revela-se mais intensa naquelas regiões em que há maior investimento em atividade de $P \& D$ por parte das empresas (Sul e Sudeste). Finalmente, os resultados indicam que a existência de instrumentos de apoio governamental ao desenvolvimento industrial tende a estimular um número maior de empresas a inovar, o que 
pode ser ilustrado pelos casos das regiões Sul e Sudeste do Brasil.

Palavras-chave: Inovação; Indicadores de inovação; Gestão da informação e do conhecimento; Inovação tecnológica empresarial.

\section{Comparative analysis of regional indicators of business technological innovation: contribution from the data of the Industry Research on Technology Innovation}

This article presents an analysis of indicators of business technological innovation. The methodology is based on broken down analysis of the data produced by the IBGE Industry Research on Innovation and Technology, according to the country's regions. Analysis of these indicators confirms the idea that innovation involves not only primarily economic elements. The Southeast region, despite being the national leader in terms of economical capacity of production, is not ranked first in technological innovation. Companies from the Northeast, North and South regions are those that show more innovative effort, compared to other regions, and are also the ones showing more innovation. The results suggest that in those regions where companies invest more in $R$ \& $D$ there is an increased concern with the protection of knowledge through patenting (South and Southeast). Finally, the results indicate that the existence of governmental supporting instruments for industrial development tends to encourage more of the industries to innovate, which can be illustrated by cases in Southern and Southeastern Brazil.

Keywords: Innovation; Indicators of innovation; Management of information and knowledge; Technological innovation business.

Recebido em 25.07.2008 Aceito em 12.03.2009 


\section{Introdução}

O processo de geração e difusão de inovações tecnológicas no nível da economia mundial constitui tema que marca profundamente os anos iniciais do século XXI. Pelo fato de se posicionar no centro das transformações associadas ao novo padrão de acumulação capitalista aqui entendido como Sociedade da Informação e do Conhecimento - e de exercer forte influência na competitividade de empresas, países e regiões, a temática relativa à inovação tecnológica vem ganhando crescente evidência nos meios científico, acadêmico, empresarial e governamental.

A premissa central deste artigo baseia-se na concepção de que a inovação tecnológica que ocorre nas empresas localizadas nos países em desenvolvimento é um processo que possui características próprias, que a diferenciam da inovação tecnológica realizada pelas empresas atuantes nos países tecnologicamente avançados. Considera-se que a empresa representa um locus privilegiado de análise do processo de inovação tecnológica. É na empresa que a inovação tecnológica de fato ocorre, a partir da cooperação com outros atores integrantes do sistema nacional, regional ou local de inovação.

Entendida como o conjunto de ações sistemáticas referentes à geração e à aplicação do conhecimento tecnológico voltado à produção de novos produtos (bens e serviços), e à introdução de novos processos produtivos pela empresas, a inovação tecnológica empresarial nos países tecnologicamente periféricos distingue-se daquela que ocorre nas economias centrais. Nestas, as empresas atuam na fronteira superior do conhecimento tecnológico mundial e, em decorrência, as inovações tendem a ser radicais. Por sua vez, nos países tecnologicamente periféricos a inovação tecnológica revela-se um processo cumulativo e gradual, portanto de natureza preponderantemente incremental (LUNDVALL, 1992; NELSON, 1993; ORGANIZAÇÃO PARA A COOPERAÇÃO E DESENVOLVIMENTO ECONÔMICO - OCDE, 1997).

Em decorrência, mecanismos e práticas de gestão capazes de promover o aprendizado organizacional das empresas emergem como vetores que influenciam a configuração do processo de inovação tecnológica dos países em desenvolvimento. Nesse sentido, torna-se fundamental aprofundar as discussões sobre um arcabouço teóricoconceitual que retrate mais adequadamente a natureza incremental da inovação que ocorre nas empresas que atuam nestes países.

A preocupação com a compreensão do fenômeno da inovação tecnológica tem motivado o desenvolvimento de metodologias e formas de se mensurá-la. Os esforços brasileiros neste campo iniciaram-se na década de 90, sendo, portanto, relativamente recentes e ainda pouco difundidos no meio acadêmico, técnico e empresarial, de modo geral (ROCHA, 2003; REDE IBEROAMERICANA DE INDICADORES DE CIÊNCIA E TECNOLOGIA - RICYT, 2001; SUTZ, 1999).

O Brasil dispõe de levantamento sistemático de abrangência nacional sobre inovação tecnológica nas empresas industriais. A 
denominada Pesquisa Industrial Inovação Tecnológica (PINTEC) é realizada pelo Instituto Brasileiro de Geografia e Estatística (IBGE), a cada três anos, e atualmente encontra-se em seu segundo período de realização. Entretanto, apenas recentemente o IBGE, em conjunto com o Ministério da Ciência e Tecnologia (MCT), disponibilizou os dados e informações da PINTEC, referentes ao período 2001-2003, desagregados segundo as cinco grandes regiões do país. Como somente a partir do segundo semestre de 2006 os dados regionais puderam ser acessados, praticamente não existem ainda na literatura especializada brasileira estudos e análises enfocando as características regionais do processo de inovação tecnológica empresarial em anos mais recentes, a partir dessa fonte específica.

O artigo pretende responder a pelo menos três questões principais. Que elementos conceituais poderiam compor um quadro teórico-conceitual capaz de retratar mais adequadamente o processo de inovação tecnológica que ocorre nas empresas que atuam nos países em desenvolvimento, que, a exemplo do Brasil, conformam um espaço tecnologicamente periférico? Qual é a experiência brasileira no que diz respeito à geração e aplicação de indicadores de inovação tecnológica no contexto das organizações empresariais? O que dizem os indicadores acerca do processo de inovação tecnológica empresarial que ocorre nas diferentes regiões do Brasil?

Um aspecto interessante dessa discussão é que, pela sua natureza multifacetada, os debates sobre inovação tecnológica empresarial, e sobre parâmetros e evidências empíricas acerca do processo de inovação, refletem a possibilidade de interpretações interdisciplinares, integrando as ciências gerenciais e administrativas, a ciência da informação e as ciências econômicas.

São três os objetivos deste artigo: (a) desenvolver um quadro teórico-conceitual que permita lidar com a natureza ao mesmo tempo nova e complexa da inovação tecnológica no contexto das organizações empresariais que atuam em países tecnologicamente periféricos; (b) traçar um panorama da experiência brasileira na área de construção de indicadores de inovação tecnológica empresarial; (c) explorar o potencial analítico dos dados e informações produzidos pela Pesquisa Industrial de Inovação Tecnológica (PINTEC), a partir da seleção e compilação de um conjunto de indicadores de inovação tecnológica das empresas localizadas nas distintas regiões do país. Acredita-se que este exercício preliminar de interpretação dos indicadores de inovação tecnológica no âmbito das distintas regiões brasileiras possa contribuir para incrementar a base empírica sobre inovação tecnológica empresarial no Brasil. 


\section{Inovação tecnológica das empresas que atuam nos países tecnologicamente periféricos: a busca por um quadro teórico-conceitual}

As perspectivas propiciadas pelo conceito de Sistema Nacional de Inovação - reconhecido genericamente como sistema de inovação desenvolvido originalmente por Freeman (1982), Lundvall (1992) e Nelson (1993), demonstram que informação, conhecimento e inovação sempre estiveram no cerne do desenvolvimento econômico das sociedades ao longo do tempo.

O enfoque de Sistema Nacional de Inovação integra a abordagem estruturalista francesa dos sistemas nacionais de produção com a visão inglesa dos estudos de inovação, e fornece elementos teóricos e conceituais importantes para uma compreensão mais ampla da inovação tecnológica.

O Sistema Nacional de Inovação pode ser compreendido como uma base ou arranjo institucional que busca consolidar um ambiente favorável à inovação tecnológica no âmbito nacional (ao referir-se ao conjunto de um país), regional ou local (sistemas regionais e locais de inovação). Essa base institucional envolve o Estado (poder público, na esfera de governo central, regional ou local), as agências governamentais, empresas, universidades e centros de pesquisa, articulados com o sistema educacional e de financiamento. O sucesso da inovação tecnológica desenvolvida pela empresa está associado, portanto, ao sistema nacional (regional ou local) de inovação (ROCHA, 2003; ALBUQUERQUE, 2001).

As implicações do enfoque baseado nos "sistemas nacionais de inovação" não se limitam às dimensões econômica e tecnológica. Consideram-se, além destes dois aspectos, o processo de aprendizagem interativa, cuja natureza é essencialmente social.

Segundo Lundvall (1992), os sistemas nacionais de inovação se baseiam em dois pressupostos. O primeiro considera o conhecimento como recurso fundamental da economia moderna, e o aprendizado o processo mais importante. Nesse pressuposto, o fato de o conhecimento diferir de outros recursos econômicos potencializa o desenvolvimento de um paradigma alternativo. O segundo pressuposto, para Lundvall (1992), considera que a aprendizagem é um processo interativo e social, somente compreendida em determinado contexto institucional e cultural. Especificamente, esse pressuposto considera que a criação e o desenvolvimento do estado moderno provocaram a aceleração do processo de aprendizagem, e que o processo de internacionalização e globalização econômica está promovendo mudanças nas formas tradicionais de apoio do estado à aprendizagem.

Em termos amplos, a inovação tecnológica pode ser entendida como um conjunto de ações sistemáticas e coordenadas, referentes à geração e à aplicação do conhecimento tecnológico voltado para a produção de novos produtos e para a introdução de novos processos produtivos pelas organizações. Considerando-se especificamente o contexto das 
organizações empresariais, pode-se definir a inovação tecnológica como o processo de introdução no mercado de um produto novo ou substancialmente melhorado, bem como a introdução, pela empresa, de um processo produtivo novo ou substancialmente aperfeiçoado (INSTITUTO BRASILEIRO DE GEOGRAFIA E ESTATÍSTICA - IBGE, 2005; ROCHA, 2003; RICYT, 2001; OCDE, 1997).

De acordo com institutos e organismos que desenvolvem metodologias de mensuração e de sistematização de dados e informações sobre inovação tecnológica empresarial, o "novo" produto ou processo possui até três anos de existência; e "substancialmente melhorado" corresponde àquele produto ou processo que passou por aperfeiçoamentos que modificaram seu desempenho funcional. A inovação tecnológica desenvolvida pela empresas pode resultar, então, de novos desenvolvimentos tecnológicos, de novas combinações de tecnologias existentes ou da utilização de outros conhecimentos adquiridos pela empresa (IBGE, 2005; INSTITUTO DE PESQUISA ECONÔMICA APLICADA IPEA, 2005; OCDE, 1997).

Mais de setenta anos após sua mais importante publicação, as idéias de Schumpeter (1934) constituem, ainda hoje, uma referência de grande relevância para a compreensão da inovação tecnológica, e resgatam um aspecto fundamental a respeito do agente econômico central do processo de inovação tecnológica. Para o autor, a empresa e a rede de relações em que se encontra inserida são protagonistas essenciais do processo de inovação e de avanço tecnológico.

Conforme argumenta Rocha (2003), a distinção quanto ao caráter "radical" versus "incremental" da inovação tecnológica e a compreensão da inovação radical como um processo de destruição criadora que se estabelece na fronteira do conhecimento tecnológico, são noções e conceitos explicitados por Schumpeter (1934).

As inovações radicais representam uma ruptura com o padrão tecnológico até então vigente, originando novos produtos, processos, setores e mercados (ou seja, representam produtos, processos, setores e formas de organização inteiramente novas). As inovações incrementais, por sua vez, referem-se à introdução de melhorias e aperfeiçoamentos em produtos, processos ou na organização da produção. O design, a combinação e adaptação de tecnologias já existentes, no sentido de se otimizar os processos de produção e a redução de materiais e componentes na produção de um bem, podem ser considerados inovações incrementais.

Outro aspecto interessante e que de alguma forma também se encontra em Schumpeter (1934) diz respeito à diferença existente entre conceitos próximos, como "invenção", "inovação" e "difusão". Invenção pode ser compreendida como a geração de uma nova peça de conhecimento tecnológico materializada em uma solução técnica que, por vezes, resulta da ação individual de um pesquisador. Inovação é o resultado cumulativo de atividades associadas à pesquisa e ao desenvolvimento e que se traduz em um novo produto ou processo, 
comercializado no mercado. Difusão diz respeito à imitação da inovação introduzida no mercado de forma pioneira por uma empresa - a partir do momento em que é adotada por um grande número de competidores ou empresas concorrentes (ROCHA, 2000; RICYT, 2001; OCDE, 1997).

Conforme se apreende de estudos e pesquisas desenvolvidos por Viotti (2004), Rocha (2003), Lastres e Albagli (1999), dentre outros, é fundamental compreender que no caso de empresas atuantes em países que, a exemplo do Brasil, possuem sistema nacional de inovação imaturo, o conceito de inovação tecnológica mais adequado é aquele associado ao caráter "incremental" da inovação tecnológica. Assim, no contexto empresarial das economias em desenvolvimento, a inovação tecnológica é um processo cumulativo, gradual, fortemente relacionado ao aprendizado organizacional interativo.

O aprendizado organizacional interativo é uma forma particular de aprendizado de grande importância e que vem ganhando relevância nos países em desenvolvimento. Trata-se da aprendizagem pela interação com fontes externas à empresa, tais como fornecedores de insumos e equipamentos, clientes, universidades e institutos de pesquisa, agências e laboratórios governamentais, consultores e licenciadores (learning by interacting) (ROCHA, 2003).

O aprendizado organizacional guarda relação com as novas configurações que o processo de gestão assume nas organizações. Apontados na literatura sobre sistemas nacionais de inovação como elementos que potencializam a inovação tecnológica empresarial, os mecanismos e práticas de gestão da informação e do conhecimento apenas recentemente têm ganhado evidência enquanto vetores de relevância no contexto dos estudos empresariais.

Choo (2003), Leonard-Barton (1998) e Fleury e Fleury (2000) entendem que o processo de inovação tecnológica de uma organização empresarial é influenciado pelas características assumidas pelas suas práticas e mecanismos de gestão da informação e do conhecimento. Estes são fatores essenciais à aquisição de informação e conhecimento e à mobilização proativa dos colaboradores de uma empresa, contribuindo positivamente para a criação de um ambiente organizacional propício à inovação ("cultura da inovação"), no qual a aprendizagem organizacional atua como elemento de interação, e, portanto, está inextricavelmente associada ao processo de inovação.

Tendo em vista as especificidades da inovação tecnológica empresarial em países tecnologicamente periféricos - caracterizados por sistemas de inovação ainda imaturos e por inovações de natureza mais incremental do que radical - acredita-se que as práticas de gestão da informação e do conhecimento nas organizações empresariais destes países representem janelas de oportunidades que permitem gerar as sinergias necessárias para a alavancagem do aprendizado organizacional, potencializando, assim, a inovação tecnológica.

A FIG. 1 ilustra os principais conceitos, definições e interações que se acredita serem relevantes para compor um quadro teórico-conceitual 
que possibilite uma melhor compreensão da inovação tecnológica que ocorre no ambiente empresarial dos países em desenvolvimento.

Sistema de Inovação: base ou arranjo institucional que busca consolidar um ambiente favorável à inovação tecnológica no âmbito nacional (ao referir-se ao conjunto de um país), regional ou local (sistemas regionais e locais de inovação), envolvendo empresas, o Estado e as agências governamentais, universidades e centros de pesquisa, articulados com o sistema educacional e de financiamento

\section{Gestão da Informação} Conjunto de ações coordenadas de registro, tratamento, recuperação, interpretação e distribuição da informação relevante para o desenvolvimento de novos produtos e processos pela empresa.

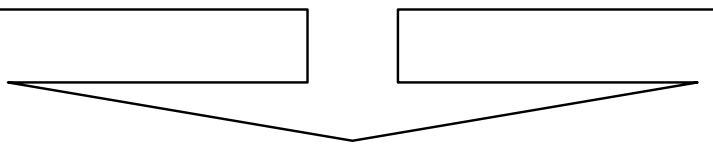

\section{Gestão do Conhecimento}

Conjunto de ações coordenadas no sentido de criar e mobilizar o conhecimento interno e externo à empresa por meio da facilitação da comunicação entre os atores envolvidos no desenvolvimento de novos produtos e processos - e do registro do conhecimento adquirido.
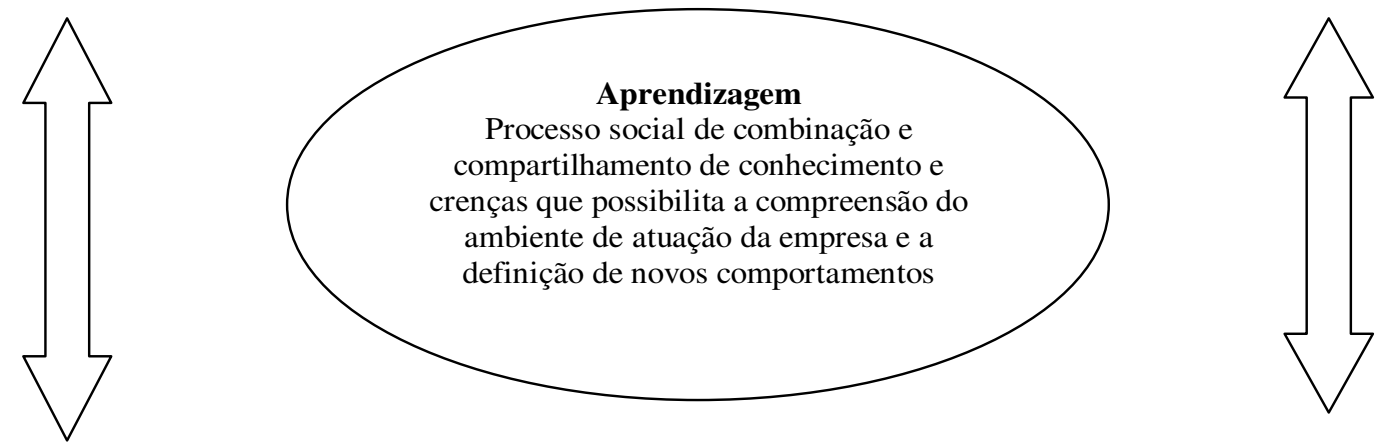

Inovação Tecnológica Empresarial

Processo de aquisição e aplicação do conhecimento voltado para o desenvolvimento e comercialização de novos produtos e ou a introdução de novos processos produtivos na empresa.

FIGURA 1 - Sistema de inovação, gestão da informação, gestão do conhecimento e aprendizagem no contexto da inovação tecnológica empresarial

Fonte: Adaptado de ROCHA(2003).

\section{Histórico do desenvolvimento dos indicadores de inovação tecnológica empresarial: a experiência brasileira recente}

O desenvolvimento de uma nova classe de indicadores revela-se como uma tarefa longa, em termos de tempo (envolve várias etapas), e árdua (é cercada de intensas discussões e polêmicas entre pares). Conforme argumenta Rocha (2003), o período que se estabelece entre o momento de concepção de uma nova classe de indicadores e a produção 
de estatísticas (indicadores reconhecidos, validados e testados) pode durar décadas.

O interesse pela mensuração da ciência e tecnologia na América Latina data dos anos 60. As experiências realizadas, diferentes em cada caso, e em geral, descontínuas, incluem praticamente todos os países da região. Os indicadores de ciência e tecnologia (C\&T) atualmente existentes nos países latino-americanos baseiam-se, principalmente, nas metodologias sugeridas pela "Família Frascati" de normas e procedimentos da Organização para a Cooperação e o Desenvolvimento Econômico (OCDE) para a mensuração de C\&T.

Entretanto, a preocupação com a mensuração da inovação tecnológica é bem mais recente. Na América Latina, os primeiros países a realizarem pesquisas de inovação com cobertura nacional, nos moldes das Community Innovation Survey (CIS), conduzidas pela OCDE foram: Uruguai, em 1986; Chile, em 1995, Colômbia em 1996; e Argentina, México e Venezuela, em 1997. Neste contexto, a iniciativa de criação da Red Iberoamericana de Indicadores de Ciência y Tecnologia (RICYT), em 1995 - a partir do apoio da UNESCO e da International Science Foundation, dos Estados Unidos da América - e a publicação, pela Rede, do Manual de Bogotá, em março de 2001, foram de grande importância para os procedimentos de sistematização de indicadores de inovação tecnológica empresarial na América Latina.

Conforme se depreende de Sutz (1999), as pesquisas nacionais então realizadas geraram informações originais e relevantes sobre inovação tecnológica, motivando as discussões sobre a natureza e as especificidades deste processo nas economias latino-americanas. Entretanto, a compilação e a interpretação de indicadores de inovação a partir de tais pesquisas foram comprometidas por dificuldades de natureza conceitual, pela falta de clareza quanto às categorias das variáveis que seriam mensuradas, bem como pelas carências e inadequações dos sistemas de informação na área de Ciência e Tecnologia existentes naqueles países.

No caso do Brasil, as experiências na área de geração de indicadores de inovação tecnológica empresarial são representadas pelas iniciativas de duas instituições: a Associação Nacional de Pesquisa, Desenvolvimento e Engenharia das Empresas Inovadoras (ANPEI), e o IBGE.

Os esforços pioneiros foram desenvolvidos pela ANPEI, organização privada, que no período 1992-2000 construiu a "Base de Indicadores Empresariais de Inovação Tecnológica", reunindo informações anuais sobre inovação tecnológica de um conjunto de empresas. O painel de empresas respondentes da ANPEI, entretanto, era bastante limitado, e no último ano correspondia a pouco mais de trezentas empresas em todo o país.

Diante da crescente demanda de informações sobre inovação tecnológica nas organizações empresariais, e considerando-se a pequena abrangência da base de dados da ANPEI, O IBGE, órgão oficial de estatísticas no Brasil, realizou então, no período 1998-2000, a primeira 
Pesquisa Industrial Inovação Tecnológica (PINTEC), de periodicidade trianual. Atualmente, a pesquisa encontra-se em sua segunda edição, que tem como referência o período 2001-2003.

Fonte única de informações sistemáticas diretas sobre o processo de inovação tecnológica nas empresas industriais, com cobertura nacional, a PINTEC investiga um amplo leque de itens sobre inovação tecnológica, e seu objetivo geral é produzir dados e informações importantes para estudiosos, pesquisadores e formuladores da política industrial, científica e tecnológica no Brasil.

\section{Metodologia}

A referência conceitual e metodológica da PINTEC é o Oslo Manual: proposed guidelines for collections and interpreting technological innovation data, publicado pela OCDE em 1997. Os dados, informações e indicadores da Pesquisa abrangem mais de cento e cinqüenta itens, entre variáveis qualitativas e quantitativas. A unidade de investigação é a empresa industrial ativa, que possui dez ou mais pessoas ocupadas.

Os levantamentos da PINTEC compõem uma base de dados e apenas recentemente, no último trimestre de 2006, o IBGE, juntamente com o Ministério da Ciência e Tecnologia (MCT), disponibilizou os dados da Pesquisa desagregados por regiões do País. Portanto, a discussão tratada neste artigo mostra-se oportuna e original, pois o potencial analítico dos dados levantados pela PINTEC ainda não foi explorado a partir do enfoque regional.

O número de empresas respondentes no total do País e nas grandes regiões é mostrado no GRÁF. 1.

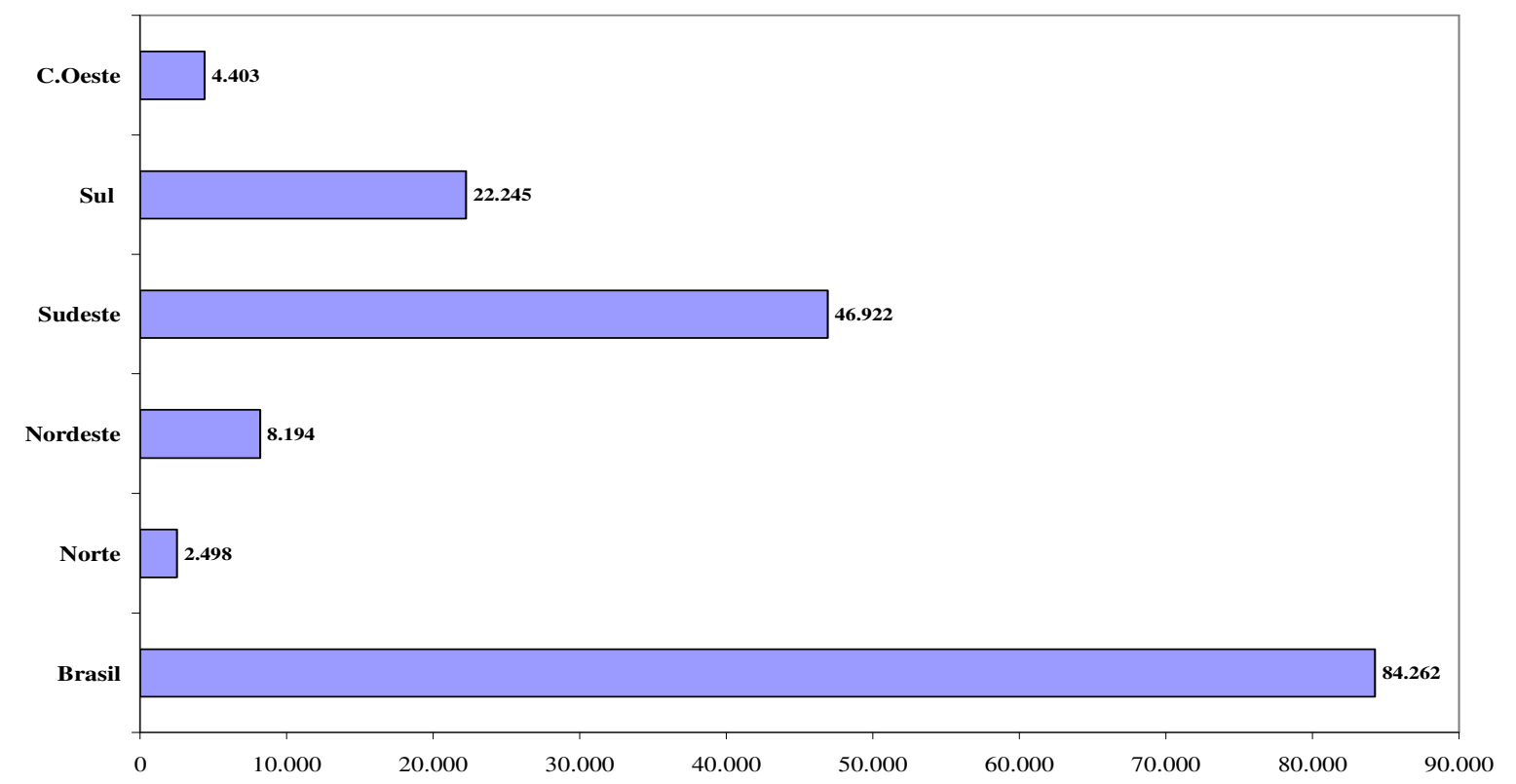

GRÁFICO 1 - Pesquisa Industrial Inovação Tecnológica - 2003: Número de Empresas Respondentes

Fonte: Pesquisa Industrial Inovação Tecnológica, PINTEC - IBGE, 2003. 
Como levantamentos nacionais semelhantes ao da PINTEC lidam com grandes volumes de dados e informações, complexas e especializadas, os mecanismos de obtenção e captura das informações requerem o uso de variados instrumentos. O IBGE obteve as informações da PINTEC através de entrevista assistida realizada com profissional da empresa integrante da equipe de pesquisa e desenvolvimento (P\&D) ou com atuação na área de produção industrial.

As entrevistas assistidas realizadas nas empresas foram de duas modalidades: (a) presenciais, para as empresas com 500 ou mais pessoas ocupadas e localizadas nos Estados do Amazonas, Alagoas, Bahia, Ceará, Pernambuco, Espírito Santo, Minas Gerais, Rio de Janeiro, São Paulo, Paraná, Rio Grande do Sul, Santa Catarina e Goiás; e (b) por telefone, nas demais empresas que possuem menos de 500 pessoas ocupadas. No caso da modalidade presencial, utilizou-se o palm top, que incorporava um sistema de entrada de dados. Já as entrevistas telefônicas foram assistidas por computador (computer assisted telephone interview, CATI).

A partir da variada gama de dados produzidos pela PINTEC, extraiuse um conjunto restrito de indicadores (sete) para discussão neste artigo, de modo a conhecer melhor a inovação tecnológica empresarial no âmbito das diferentes regiões do Brasil, no que diz respeito aos seguintes aspectos principais: esforço de inovação empreendido pelas empresas, amplitude e intensidade da inovação tecnológica realizada pelas empresas, utilização do mecanismo de proteção do conhecimento por meio de patentes, e apoio governamental às empresas que atuam nas diferentes regiões do Brasil.

A relação dos indicadores, a unidade de medida e o significado dos indicadores de inovação tecnológica extraídos da PINTEC 2003 encontramse dispostos abaixo (QUADRO 1). 
QUADRO 1- Indicadores de Inovação Tecnológica Selecionados da PINTEC 2003

\begin{tabular}{|c|c|c|}
\hline Indicador & Unid. & Significado \\
\hline 1) Esforço Inovador & $\%$ & $\begin{array}{l}\text { Mensura o valor do dispêndio das empresas em atividades inovativas em relação à } \\
\text { receita líquida de vendas. São consideradas atividades inovativas: desenvolvimento } \\
\text { interno de pesquisa e desenvolvimento }(\mathrm{P} \& \mathrm{D}) \text {, aquisição externa de } \mathrm{P} \& \mathrm{D} \text {, aquisição de } \\
\text { máquinas e equipamentos, treinamento, introdução de inovações tecnológicas no } \\
\text { mercado e projeto industrial. }\end{array}$ \\
\hline 2) Intensidade Tecnológica & $\%$ & $\begin{array}{l}\text { Valor dos dispêndios das empresas inovadoras com a atividade de pesquisa e } \\
\text { desenvolvimento }(\mathrm{P} \& \mathrm{D}) \text {, em relação à receita líquida de vendas. A atividade de } \mathrm{P} \& \mathrm{D} \\
\text { compreende o trabalho criativo, empreendido de forma sistemática, com o objetivo de } \\
\text { aumentar o acervo de conhecimentos e o uso destes para desenvolver novas } \\
\text { aplicações, tais como produtos ou processos novos ou tecnologicamente aprimorados; } \\
\text { o desenho, a construção e o teste de protótipos e de instalações-piloto, além do } \\
\text { desenvolvimento de software, que envolva avanço tecnológico ou científico. }\end{array}$ \\
\hline 3) Taxa de Inovação & $\%$ & $\begin{array}{l}\text { Corresponde ao percentual do número de empresas que implementaram inovação de } \\
\text { produto ou processo em relação ao total de empresas respondentes. }\end{array}$ \\
\hline 4) Mecanismo de Patenteamento-Painel de Respondentes & $\%$ & $\begin{array}{l}\text { Participação percentual do número de empresas com depósito de patente e patente em } \\
\text { vigor, em relação ao número total de empresas respondentes. }\end{array}$ \\
\hline 5) Uso do Mecanismo de Patenteamento-Empresas Inovadoras & $\%$ & $\begin{array}{l}\text { Participação percentual do número de empresas inovadoras com depósito de patente e } \\
\text { patente em vigor, em relação ao número total de empresas inovadoras. }\end{array}$ \\
\hline 6) Suporte Governamental-Painel de Respondentes & $\%$ & $\begin{array}{l}\text { Percentual do número de empresas que receberam suporte do governo para as } \\
\text { atividades inovadoras em relação ao número total de empresas respondentes. }\end{array}$ \\
\hline 7) Suporte Governamental-Empresas Inovadoras & $\%$ & $\begin{array}{l}\text { Percentual do número de empresas que receberam suporte do governo para as } \\
\text { atividades inovadoras em relacão ao número de empresas inovadoras. }\end{array}$ \\
\hline
\end{tabular}

Fonte: PINTEC 2003 e autor.

\section{Análise dos indicadores}

Os valores obtidos para os indicadores de inovação tecnológica empresarial, compilados a partir dos dados da PINTEC 2003, são apresentados no QUADRO 2, e são analisados a seguir.

$O$ indicador do esforço inovador mostra o percentual da receita líquida investido pelas empresas nas atividades inovadoras e, neste quesito, os dados indicam que as empresas das regiões Nordeste $(2,88 \%)$, Norte $(2,63 \%)$ e Sul $(2,59 \%)$ são as que realizam maior esforço inovador, comparativamente às outras regiões.

Dentre as atividades que as empresas realizam para potencializar o desenvolvimento de novos produtos e processos, aquelas relacionadas à pesquisa e desenvolvimento (P\&D) são particularmente relevantes, uma vez que tendem a exercer forte influência na configuração do processo de inovação nas empresas, em função, sobretudo, da natureza deste tipo de atividade inovadora. As atividades de P\&D interna contribuem para aumentar o acervo de conhecimentos tecnológicos e o uso destes para desenvolver novas aplicações (produtos e processos tecnologicamente novos ou aprimorados, construção de protótipos, elaboração de testes e desenvolvimento de software, dentre outros).

A este respeito, pelo menos dois aspectos merecem ser ressaltados. Primeiramente, constata- se que, de modo geral, são baixos os valores dos indicadores de intensidade tecnológica, o que indica serem proporcionalmente pequenos os dispêndios das empresas com a atividade de P\&D interna - não chegam a alcançar $1,0 \%$ do valor da receita líquida. 
QUADRO 2 - PINTEC 2003: Valores dos Indicadores de Inovação Tecnológica - Brasil e Grandes Regiões do País.

\begin{tabular}{|c|c|c|c|c|c|c|c|}
\hline Especificação & Unid. & Brasil & Norte & Nordeste & Sudeste & Sul & C.Oeste \\
\hline Taxa de Inovação & $\%$ & 33,27 & 34,91 & 32,38 & 31,38 & 37,72 & 31,71 \\
\hline Esforço Inovador & $\%$ & 2,46 & 2,63 & 2,88 & 2,40 & 2,59 & 1,61 \\
\hline Intensidade Tecnológica & $\%$ & 0,53 & 0,51 & 0,18 & 0,62 & 0,39 & 0,09 \\
\hline Importância Econômica da Inovação & $\%$ & 38,41 & 60,41 & 32,28 & 36,39 & 37,13 & 64,80 \\
\hline Uso do Mecanismo de Patentes-Painel de Respondentes & $\%$ & 3,70 & 1,76 & 1,57 & 3,87 & 4,78 & 1,54 \\
\hline Uso do Mecanismo de Patentes-Empresas Inovadoras & $\%$ & 11,13 & 5,05 & 4,86 & 12,33 & 12,67 & 4,87 \\
\hline Suporte Governamental-Painel de Respondentes & $\%$ & 6,21 & 7,97 & 7,04 & 5,17 & 7,76 & 6,90 \\
\hline Suporte Governamental-Empresas Inovadoras & $\%$ & 18,67 & 22,82 & 21,75 & 16,47 & 20,58 & 21,78 \\
\hline
\end{tabular}

Fonte: Pesquisa Industrial Inovação Tecnológica, PINTEC 2003. IBGE.

Em segundo lugar, os dados indicam que as empresas da região Sudeste $(0,62 \%)$, seguidas da Norte e Sul $(0,51 \%$ e $0,39 \%$, respectivamente) são aquelas que apresentam maior intensidade tecnológica.

A taxa de inovação, por sua vez, constitui-se um indicador da amplitude da inovação tecnológica no contexto do parque industrial, e sua interpretação no âmbito das diferentes regiões do País revela que a Região Sul $(34,91 \%)$, seguida pela Norte $(33,27 \%)$ e Nordeste $(32,38 \%)$, são aquelas que apresentam maior taxa de inovação. Ou seja, estas três regiões são aquelas que abrigam maior número de empresas inovadoras proporcionalmente ao parque industrial existente em cada região.

É interessante observar que a região Sudeste, que do ponto de vista da capacidade econômica de produção (mensurada em termos de Produto Interno Bruto, PIB) possui posição de liderança no País, não apresenta o mesmo destaque no que diz respeito à amplitude da inovação tecnológica. Regiões como Sul, Norte e o Nordeste do País, que detêm capacidade econômica de produção relativamente menor, possuem proporcionalmente mais empresas inovadoras do que o Sudeste, onde o parque industrial é maior e mais diversificado. Este resultado sugere que, para efeitos de inovação tecnológica, fatores outros, que não apenas a magnitude da capacidade econômica de produção, exercem influências na configuração da inovação no âmbito regional.

A patente constitui-se importante mecanismo de proteção do conhecimento tecnológico empresarial, por meio do qual as organizações empresariais tentam garantir a apropriação dos resultados de suas inovações e proteger seus mercados. A este respeito, pelo menos três considerações merecem ser destacadas.

Primeiramente, constata-se, de modo geral, que o mecanismo de patentes é ainda pouco utilizado pelas empresas brasileiras. Em termos médios, apenas 3,7\% das empresas da amostra de respondentes, e em torno de $11,0 \%$ das empresas inovadoras, declararam possuir depósito de patente ou patente em vigor. 
Em segundo lugar, ao se comparar o indicador de patente entre o grupo geral das empresas respondentes da PINTEC e o grupo de empresas inovadoras, observa-se, em todas as regiões, que o grupo de empresas que desenvolvem produtos e processos tecnologicamente novos revela maior preocupação com o mecanismo de patente, comparativamente ao grupo geral de empresas (maior percentual para o grupo de empresas inovadoras vis a vis ao grupo de respondentes em cada uma das regiões).

Em terceiro, ao se comparar os indicadores de patentes das empresas inovadoras das distintas regiões do país, constata-se que o mecanismo de patente encontra-se relativamente mais desenvolvido nas regiões Sul $(12,67 \%)$ e Sudeste $(12,33 \%)$, comparativamente às demais regiões. Assim, conforme seria de se esperar no caso das empresas inovadoras, a preocupação com a proteção do conhecimento por meio de patentes revela-se maior naquelas regiões em que há maior intensidade tecnológica (maior investimento em P\&D por parte das empresas).

Pela natureza estratégica que assume no cenário da competitividade econômica mundial e pela complexidade que suas atividades envolvem, 0 processo de inovação tecnológica vem recebendo crescente apoio governamental nos diversos países do mundo. A percepção de que o amadurecimento dos sistemas nacionais (regionais e locais) de inovação depende da articulação institucional entre os distintos atores que o integram (empresas, governo, universidades, centros e institutos de pesquisa, órgãos de fomento e financiamento) tem influenciado o desenho de diferentes formas de apoio governamental à inovação tecnológica.

Para efeitos da PINTEC, o IBGE considera como apoio governamental à inovação tecnológica das empresas os seguintes mecanismos: financiamentos, incentivos fiscais, subvenções, fundos setoriais e participação em programas públicos voltados para o desenvolvimento científico e tecnológico, entre outros.

Pela análise dos indicadores correspondentes, constata-se ser pequena a proporção de empresas que recebem suporte governamental: percentual médio de apenas $6,2 \%$ das empresas do painel geral de respondentes, e de aproximadamente 18,7\% das empresas inovadoras.

Por outro lado, há indícios de que os instrumentos de apoio governamental - mais especificamente aqueles estabelecidos no âmbito da Política Industrial, Tecnológica e de Comércio Exterior, PITCE - estejam sendo relativamente mais utilizados pelo grupo de empresas inovadoras do que pelo grupo geral de empresas respondentes. Tal situação é ilustrada pelo fato de, em todas as regiões do País, o indicador de apoio governamental para o grupo de empresas inovadoras mostrarem-se mais elevados do que para o grupo geral de empresas respondentes da PINTEC.

Outro aspecto que emerge da análise é o fato de, no grupo de empresas inovadoras, aquelas que mais receberam apoio governamental encontrarem-se localizadas nas regiões Norte (22,8\%), Centro-Oeste $(21,8 \%)$ e Nordeste $(21,7 \%)$. Estas regiões possuem reconhecido 
destaque no que diz respeito às operações de alguns dos principais fundos setoriais de ciência e tecnologia, a exemplo do CT-Amazônia. Portanto, há indícios de que os instrumentos de apoio governamental ao desenvolvimento industrial nas regiões Norte e Nordeste, principalmente, estejam estimulando um número maior de empresas a inovar em produtos e processos tecnologicamente novos ou aprimorados.

\section{Conclusões}

Para melhor compreender o processo de inovação tecnológica que ocorre nas empresas que atuam em espaços tecnologicamente periféricos, como é o caso brasileiro, é importante que mecanismos de modernização da gestão empresarial sejam incorporados à abordagem de "sistemas nacionais, regionais e locais de inovação". Nestes espaços, a inovação é um processo essencialmente incremental e gradual que apresenta fortes sinergias com o aprendizado organizacional. Práticas de gestão que, a exemplo da gestão da informação e do conhecimento, promovem o aprendizado nas empresas, tendem a influenciar a configuração da inovação tecnológica nestes espaços e, portanto, julga-se importante serem incorporadas ao referencial teórico-conceitual que busca melhor compreender e dimensionar a inovação tecnológica das empresas que atuam nos países em desenvolvimento.

A experiência brasileira de geração de indicadores de inovação tecnológica empresarial é relativamente recente, e pode ser retratada pelos esforços empreendidos pela ANPEI e pelo IBGE.

A análise dos indicadores de inovação tecnológica empresarial nas regiões do Brasil apresentou resultados importantes. Primeiramente, o conjunto de indicadores analisados confirma a idéia de que a inovação tecnológica mostra-se um fenômeno cuja configuração envolve elementos outros que não apenas a magnitude da capacidade econômica de produção das empresas. Os benefícios decorrentes de sinergias criadas através da atuação em setores de produtos de maior valor agregado, que utilizam mais intensamente informação e conhecimento em seu processo produtivo - a exemplo do complexo eletroeletrônico, no Amazonas, região Norte do País e do pólo petroquímico da Bahia, Nordeste -, e a existência de apoio governamental, como financiamentos e fundos setoriais e subvenções econômicas, são, também, fatores que influenciam a configuração da inovação tecnológica empresarial no âmbito das distintas regiões do país.

Outro resultado importante diz respeito à relação existente entre investimentos das empresas em P\&D e patentes. As empresas que gastam relativamente mais com as atividades internas de $P \& D$ revelam maior preocupação em proteger o conhecimento empresarial por meio de patentes, como é o caso daquelas que atuam na região Sudeste do País.

Outros resultados importantes desta análise dizem respeito às evidências sobre o baixo valor dos gastos das empresas com a atividade interna de pesquisa e desenvolvimento (não chegam a alcançar $1,0 \%$ da 
receita líquida), e ao baixo número de empresas que recebem apoio governamental.

Finalmente, o conjunto de indicadores analisados é compatível com a idéia de que cabe ao Estado importante papel na promoção da inovação tecnológica. As regiões em que as empresas recebem maior apoio do governo exibem maiores taxas de inovação, uma vez que a existência destes mecanismos de apoio estimula um maior número de empresas a inovar.

\section{Referências}

ALBUQUERQUE, E. M. Sistema Estadual de Inovação de Minas Gerais: um balanço introdutório e uma discussão do papel (real e potencial) da FAPEMIG para a sua construção. Belo Horizonte: Ed. UFMG, 2001.

CHOO, C. W. A Organização do Conhecimento: como as organizações usam a informação para criar significado, construir conhecimento e tomar decisões. São Paulo: SENAC, 2003.

FLEURY, C. A.; FLEURY, M. T. Estratégias empresariais e formação de competências: um quebra-cabeça caleidoscópico da indústria brasileira. São Paulo: Atlas, 2000.

FREEMAN, C. The economics of industrial innovation. London: Pinter, 1982.

INSTITUTO BRASILEIRO DE GEOGRAFIA E ESTATÍSTICA - IBGE. Pesquisa industrial: inovação tecnológica. Pintec 2003. Rio de Janeiro: IBGE, 2005.

INSTITUTO DE PESQUISA ECONÔMICA APLICADA - IPEA. Brasil: o estado de uma nação. Rio de Janeiro: IPEA, 2005.

LASTRES, H. M. M.; ALBAGLI, S. Introdução. In: LASTRES, H. M. M.; ALBAGLI, S. (Orgs.). Informação e globalização na era do conhecimento. Rio de Janeiro: Campus, 1999. p.7-26.

LEONARD-BARTON, D. Nascentes do saber: criando e sustentando as fontes de inovação. Rio de Janeiro: Fundação Getúlio Vargas, 1998.

LUNDVALL, B. A. (Ed.). National systems of innovation: towards a theory of innovation and interactive learning. New York: Oxford University, 1992.

NELSON, R Technical innovation and national systems. In: NELSON, R. (Ed.). National innovation systems: a comparative analysis. New York: Oxford University, 1993.

ORGANIZAÇÃO PARA A COOPERAÇÃO E DESENVOLVIMENTO ECONÔMICO OCDE. Oslo Manual: OECD proposed guidelines for collecting and interpreting technological innovation data. Paris, 1997.

REDE IBEROAMERICANA DE INDICADORES DE CIÊNCIA E TECNOLOGIA RICYT. Manual de Bogotá: normalización de indicadores de innovación tecnológica en América Latina y el Caribe. Bogotá, marzo 2001. 
ROCHA, E. M. P.; FERREIRA, M. A. T. Analysis of Brazilian technological innovation indicators: assessing the impact of privatization on innovation. In: INTERNATIONAL CONFERENCE ON TECHNOLOGY POLICY AND INNOVATION, 4. Book of abstracts. Curitiba: Ed. PUC-PR, 2000.

ROCHA, E. M. P. Indicadores de inovação: uma proposta a partir da perspectiva da informação e do conhecimento. 2003. 264 f. Tese (Doutorado em Ciência da Informação) - Escola de Ciência da Informação, Universidade Federal de Minas Gerais, Belo Horizonte, 2003.

SCHUMPETER, J. The theory of economic development. Massachusetts: Harvard University, 1934.

SUTZ, J. La innovación realmente existente en América Latina: medidas e lecturas. In: CASSIOLATO, J. E.; LASTRES, H. (Orgs.) Globalização e inovação globalizada: experiências de sistemas locais no âmbito do mercosul e proposições de políticas de C\&T. Brasília: IBICT/MCT, 1999.

VIOTTI, E.B. Technological learning systems, competitiveness and development. Brasilía: IPEA, 2004. (Texto para Discussão, n. 1057). Disponível em: <www.ipea.gov.br>. Acesso em: 23 nov. 2004. 